\title{
Ethical approval for all studies involving human participants
}

\author{
John Fletcher MB BChir MPH
}

$\mathrm{S}$ hould ethical approval be required before undertaking nonexperimental medical studies, such as audit, cohort and quality-improvement studies? Until recently, the International Committee of Medical Journal Editors (ICMJE) was silent on this matter, requiring evidence of prior ethical approval for experimental studies, but leaving it to journal editors and reviewers to decide whether an observational study had been undertaken in an ethical manner. However, ICMJE guidance has recently been updated to suggest that ethical approval be sought before any research involving humans is undertaken. ${ }^{1}$ Guidance from the Committee on Publication Ethics, an international member organization of more than 9000 journals, also suggests that all research should be subject to prior ethical review as a condition of publication, ${ }^{2}$ while recognizing that, in some countries, reports on audits and quality improvement may not require ethical approval.

It is tempting to differentiate between study designs when deciding if prior ethical approval is required. Quality-improvement projects, clinical practice audits, health services research, and clinical research that uses routine data are designs in which participants are thought to be at minimal risk of harm. Some argue that ethical review need not be sought in advance when conducting these studies. However, any attempt to classify certain study designs as universally unproblematic from an ethical standpoint misses the mark and puts patients at risk from inexperienced or unscrupulous researchers.

Although in some observational studies patients are not exposed to experimental treatments, there are other potential sources of harm. These include breach of confidentiality, the use of intrusive outcome measures (e.g., questionnaires, extra tests or more hazardous tests), expense and time involved in extra visits, and increased surveillance that may lead to anxiety and unnecessary investigation.

The judgment of the ethical acceptability of a study is best undertaken by a third party in advance of the study being conducted. In most cases, this third party should be an ethics committee or institutional review board. Researchers have a duty to carry out research to high ethical standards, but it is not safe to allow researchers themselves to decide that their study is exempt from the need for ethical review. Patients cannot undertake this role because they are vulnerable and have far less information than the researchers, who may also be their doctors. Obtaining informed patient consent for a study is necessary, but providing information does not automatically protect against exploitation and coercion. Third-party ethical review is required for this. Journal editors have a role to play as a third party, but their judgment of a particular manuscript comes too late to protect the interests of participants. Because the point of subjecting studies to ethical review is to protect patients from possible harm, any consideration of whether the interests of patients are adequately safeguarded must take place before the study is undertaken.

The present system of review and approval by the relevant body, such as an institutional review board, works well for experimental studies. However, applying review-by-committee to every proposed health study is not feasible, because it is timeconsuming, and institutions do not have the resources to do this. Institutions need to develop mechanisms that provide researchers with evidence of third-party ethical review of their study without necessarily requiring a full committee process.

A promising approach is one that involves a screening process, such as that used at Massey University, New Zealand. ${ }^{3}$ University researchers are required to complete a questionnaire before undertaking a study that involves humans. The questionnaire asks 24 questions covering risk of harm, informed voluntary consent, privacy, deception, conflict of interest, financial inducement of participants and requirements of outside organizations. If the study passes screening, it is assessed as low risk and subject to streamlined ethical review without a full committee hearing. In the United Kingdom, many local research ethics committees will empower the chair or secretary of the committee to confirm that appropriate study proposals are ethically sound without recourse to a full committee. These approaches strike a balance, providing some degree of third-party screening and approval while avoiding bureaucracy for low-risk studies.

It is not contentious that clinical trials must have ethical review before researchers may recruit the first participant, and this should become the norm for all medical studies. In future, $C M A J$ strongly encourages authors of any study type, experimental or observational, involving humans as participants to show that their study was judged as ethical by the appropriate local or national ethical body before the study was started. This will reassure editors that the study was conducted according to appropriate ethical standards as required by guidance from the ICMJE and the Committee on Publication Ethics. Researchers should make this guidance known to their ethical review bodies and seek a streamlined approval process for low-risk observational studies to avoid jeopardizing future publication of their own work.

See references, www.cmaj.ca/lookup/suppl/doi:10.1503/cmaj.141538/-/DC1

Competing interests: See www.cmaj.ca/site/misc/cmaj_staff.xhtml

Affiliation: Editor-in-Chief, CMAJ

Correspondence to: $C M A J$ editor, pubs@cmaj.ca

CMAJ 2015. DOI:10.1503/cmaj.141538 